\title{
Longitudinal trends of remodeling mechanisms after acute myocardial infarction based on severity of ischemic insult: A quantitative MRI study
}

\author{
Nilesh R Ghugre ${ }^{*}$, Jennifer Barry', Beiping Qiang ${ }^{1}$, John J Graham², Kim Connelly², \\ Alexander J Dick ${ }^{3}$, Graham A Wright ${ }^{1}$
}

From 2011 SCMR/Euro CMR Joint Scientific Sessions

Nice, France. 3-6 February 2011

\section{Introduction}

In acute myocardial infarction (AMI), the aim of any therapeutic intervention is to reduce the infarct size and attenuate adverse remodeling. The type and extent of infarction encountered clinically [transmural, hemorrhagic, heterogeneous, with microvascular obstruction (MVO)], is primarily determined by the severity of the initial ischemic insult. Understanding the in-vivo pathophysiological mechanisms after AMI as a function of severity will be key in predicting functional recovery, prognosis and assessing the efficacy of novel therapies.

\section{Purpose}

To evaluate longitudinal fluctuations in edema, hemorrhage and vasodilatory function in infarcted and remote territories of porcine myocardium following different ischemic insult durations.

\section{Methods}

The study involved two groups of animals that were subjected to balloon occlusion of the LAD $[90 \mathrm{~min}$ $(\mathrm{N}=4)$ and $45 \min (\mathrm{N}=3)$ ], followed by reperfusion. Imaging was performed on a 3T MRI scanner (MR 750, GE Healthcare) pre-LAD occlusion, at day-2 as well as weeks- 1,2,4 and 6 post-LAD occlusion. Edema was evaluated by $\mathrm{T} 2$ quantification using a $\mathrm{T} 2$-prepared spiral sequence and hemorrhage was identified by $\mathrm{T} 2 *$ determined using a multi-echo gradient-echo acquisition. Vasodilatory function was assessed at rest and

\footnotetext{
${ }^{1}$ Sunnybrook Health Sciences Centre, Toronto, ON, Canada
}

Full list of author information is available at the end of the article following Dipyridamole administration (stress), noting BOLD-induced T2 alterations. Non-infarcted basal myocardium was also analyzed to study remote zone remodeling. A contrast-enhanced IR-GRE sequence was used for infarct assessment.

\section{Results}

Figure 1 demonstrates contrast-enhanced short-axis slices from representative animals subjected to 90 and

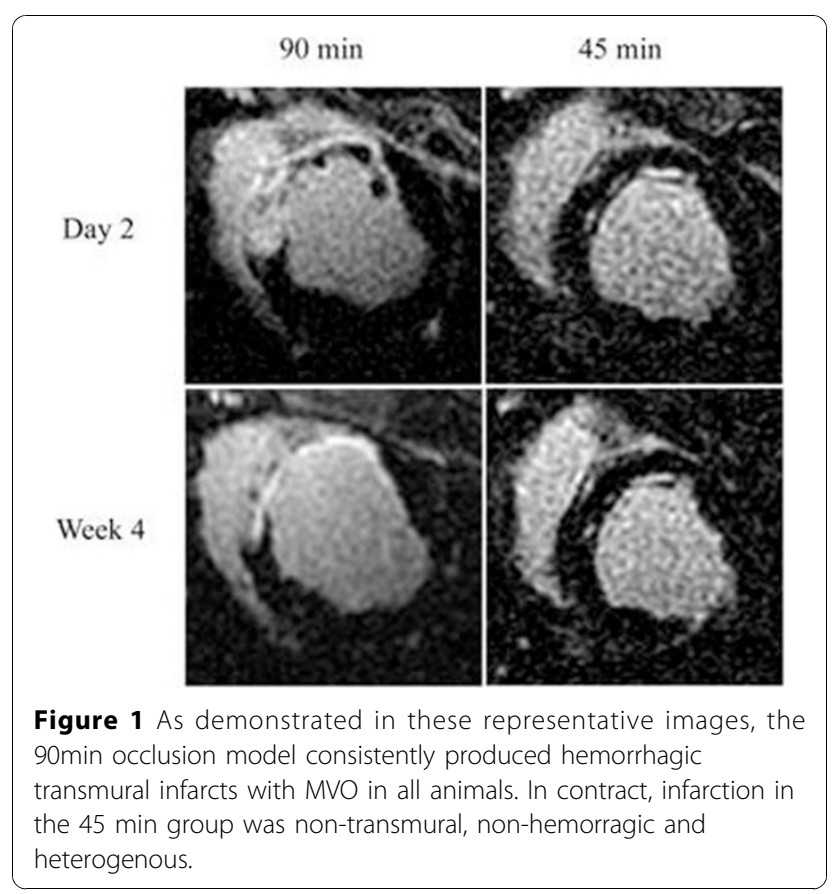

(c) 2011 Ghugre et al; licensee BioMed Central Ltd. This is an open access article distributed under the terms of the Creative Commons 
45 min occlusion shown at day- 2 and week- 4 post-AMI. In the infarct zone, the 90 min group demonstrated significant elevation in resting T2 (Fig. 2a), persisting at week-6 $(\mathrm{p}<0.005)$ that was unchanged by stress. In the 45 min group, T2 values had normalized by week- 6 (Fig. 2d) with non-significant elevation under stress. Vasodilatory function in the remote zone normalized after week-2 in the 45 min group (Fig. 2e) whereas it demonstrated prolonged impairment beyond week-2 in the 90 min animals (Fig. 2b). In the infarct zone of the $90 \mathrm{~min}$ group, $\mathrm{T}^{*}$ was significantly depressed between day-2 and week-2 $(\mathrm{p}<0.05)$ while it remained unaffected throughout infarct healing in the 45 min group.

\section{Conclusions}

Quantitative in-vivo MRI evaluation of disease evolution can distinguish longitudinal trends of the underlying remodeling processes based on severity of the ischemic insult. MRI parameters revealed faster resolution of edema and earlier restoration of vasodilatory function in
$90 \mathrm{~min}$

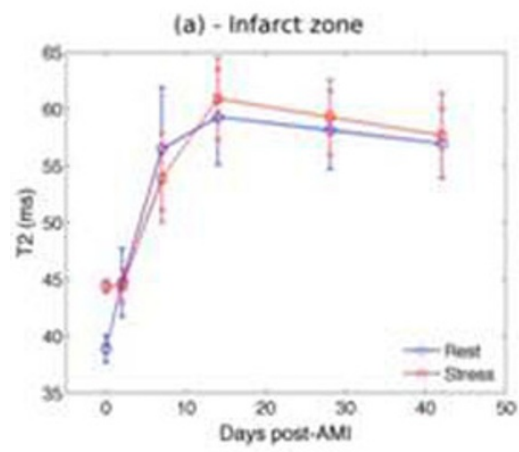

(b) - Remote zone

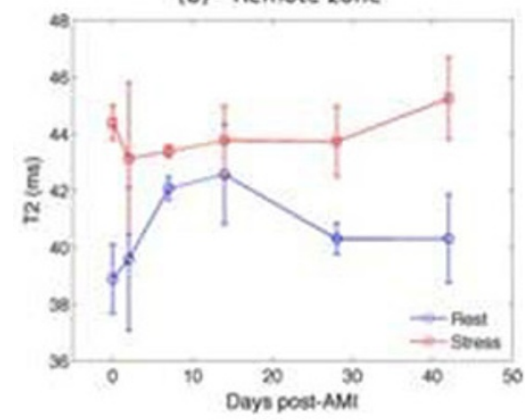

(c)

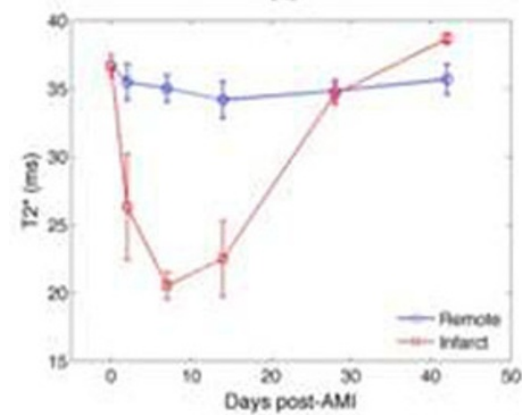

\section{$45 \mathrm{~min}$}

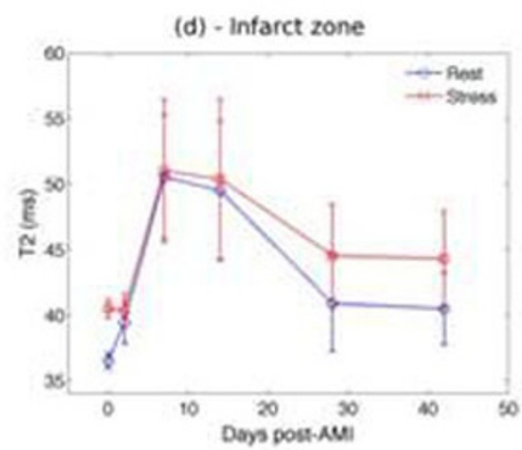

(e) - Remote zone

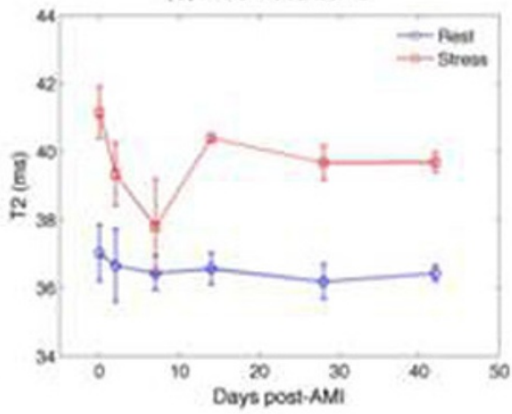

(f)

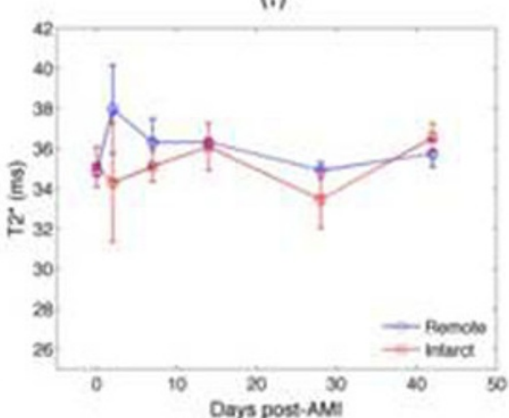

Figure 2 Cumulative time course of T2 and T2* parameters post-AMl pooled across all animals in the 90 (a-c) and 45 (d-f) min sub-groups: error bars show standard error and day 0 indicates control MRI. (a), (d) represent fluctuations in T2 within infarct zone while (b), (c) represent remote zone under rest and stress states. (c), (f) demonstrates T2* alterations in infarct and remote zones. At week 6, edema was apparent in the $90 \mathrm{~min}$ group where as it was significantly reduced in the $45 \mathrm{~min}$ group suggesting a quicker resolution of inflammatory response. 
less severe infarcts potentially indicating reduced adverse remodeling. This characterization may allow evaluation of novel therapies targeted to alleviate ischemic injury and prevent $\mathrm{MVO} /$ hemorrhage.

\section{Author details}

'Sunnybrook Health Sciences Centre, Toronto, ON, Canada. ${ }^{2}$ St. Michael's Hospital, Toronto, ON, Canada. ${ }^{3}$ University of Ottawa Heart Institute, Ottawa, ON, Canada.

Published: 2 February 2011

\section{doi:10.1186/1532-429X-13-S1-057}

Cite this article as: Ghugre et al:: Longitudinal trends of remodeling mechanisms after acute myocardial infarction based on severity of ischemic insult: A quantitative MRI study. Journal of Cardiovascular Magnetic Resonance 2011 13(Suppl 1):O57.

Submit your next manuscript to BioMed Central and take full advantage of:

- Convenient online submission

- Thorough peer review

- No space constraints or color figure charges

- Immediate publication on acceptance

- Inclusion in PubMed, CAS, Scopus and Google Scholar

- Research which is freely available for redistribution

Submit your manuscript at www.biomedcentral.com/submit 